\title{
An Exploration of BPM Adoption Factors: Initial Steps for Model Development
}

\author{
Renata Gabryelczyk \\ University of Warsaw \\ Faculty of Economic Sciences \\ ul. Długa 44/50, \\ 00-241 Warszawa, Poland \\ Email: r.gabryelczyk@wne.uw.edu.pl
}

\begin{abstract}
The main aim of the proposed research is to identify factors that create an environment conducive to successful Business Process Management (BPM) adoption. Factors predicting successful BPM adoption have been identified within the TOE (Technology-OrganizationEnvironment) framework using a literature review and methodology for constructing conceptual frameworks. The following factors are proposed: top management support for previous projects of organizational change, complexity of BPM system and notation, satisfaction with existing systems, businessIT alignment level, perceived strategic benefits of using BPM, extent of coordination, organizational readiness, performance measurement, culture conducive to organizational change, and, perceived environmental pressure. Study results have the potential to fill the research gap by contributing to the development of a theoretical model of BPM adoption that has not been proposed in studies thus far. In practical aspects, the proposed study can influence the understanding of the factors predicting successful BPM adoption.
\end{abstract}

\section{INTRODUCTION}

$\mathrm{T}$ HE main aim of the proposed research is to identify factors that create an environment receptive for Business Process Management (BPM) adoption and allow the prediction of successful adoption and use of this management concept.

BPM has been developing for over 25 years in Information Systems (IS) research [17], [14] and also in management practice [44]. BPM combines the identification, modeling, automation, implementation, control, measurement and improvement of business processes to support organizational goals and increase its effectiveness and efficiency [39]. In each of these BPM areas there are a number of studies, which, however, lack a coherent, theoretical adoption model [23], [16]. This evident gap in BPM research and expected contribution for theory and practice are the main motivations for this proposed study.

The term "adoption", in the context of this research, is defined as the use and acceptance of BPM assumptions in an organization relating to: process-based organizational structures, employee communication, process documentation, process execution, use of IT tools to support implementation and control of processes, performance measurement, process ownership, and taking into account customer requirements [33]. The level of organization involvement in BPM initiatives and programs determines process maturity, i.e., the higher the process maturity of an organization, the higher the level of BPM adoption. However, we can examine closer process maturity only when the organization decides to adopt BPM and starts the first associated initiatives and programs. In the proposed study, we identify technological, organizational and environmental conditions that are conducive to the successful adoption of BPM before the decision on this adoption is taken. Therefore, the BPM adoption model refers to factors that are predictors of the successful use and acceptance of BPM and are conducive to the development of BPM maturity.

BPM adoption factors, to the best of our knowledge, have not been identified thus far. Therefore, they need initially to be understood and they merit in the first step systematic literature review and qualitative approach [43], [20]. Thus, this research aims at the identification of the initial list of BPM adoption factors, based on a systematic literature review on BPM Critical Success Factors and of a methodology of qualitative research for constructing conceptual frameworks by Jabareen [20]. To group BPM adoption factors the TOE (Technology-Organization-Environment) framework was used as one of the most recognized concepts for innovative solutions adoption on the organizational level [41], [4]. The proposed study is an indispensable basis for the initial formulation of research hypotheses for the BPM adoption model.

The BPM adoption model should elucidate what factors predict successful BPM use in an organization, and, as a model to develop a theory, it should provide predictability based on clearly defined assumptions and be precise and falsifiable [37]. These reasons led to the proposed use of the TOE. The TOE framework was introduced by Tornatzky and Fleischer in 1990 [41] to indicate widespread theoretical

This work was supported by the Polish National Science Centre, Poland, Grant No. 2017/27/B/HS4/01734 
perspective on factors influencing business innovation in organizations. This framework explains how a technological, organizational, and environmental context influences the adoption and implementation of innovations [41], [4].

BPM as a driver of organizational innovation [36, pp. 3-15] enables the development and implementation of process innovations [32], [40]. Previous research on BPM indicates that not only are resources within an organization important for BPM adoption, but also in the broadly understood context and external environment [44]. There is also strong evidencebased research showing a relationship between Information Systems (and general Information Technology) and BPM in organizations [1], [22], [27], [13]. These arguments led to the use of the TOE framework within a technological, organizational, and environmental context as the theoretical lens of BPM adoption's determinants.

Thus, to realize the main aim of the proposed research three research questions are formulated in this study:

RQ1: Which technological factors are conducive to successful BPM adoption?

RQ2: Which organizational factors are conducive to successful BPM adoption?

RQ3: Which environmental factors are conducive to successful BPM adoption?

This paper will be organized as follows: firstly, the literature underlying the BPM adoption will be presented, followed by a literature review on BPM Critical Success Factors (CSFs) and the factors identified in the research using the TOE framework. Next, the research methodology and obtained results will be presented. Finally, a discussion, contribution, and direction of future research will be also proposed.

\section{BACKGROUND}

\section{Adoption of BPM}

The topic of BPM is widely explored in empirical research [17] and used in organizations primarily to increase organizational effectiveness, prepare organizations to implement IT systems and increase customer satisfaction [29], [42]. One common definition of BPM is proposed in [39, p. 87]: "Business Process Management (BPM) is a discipline involving any combination of modeling, automation, execution, control, measurement, and optimization of business activity flows in applicable combination to support enterprise goals, spanning organizational and system boundaries, and involving employees, customers, and partners within and beyond the enterprise boundaries". This definition was created as a result of a broad discussion of the researchers of the phenomenon and practitioners of BPM implementation, and because it covers both, the BPM technological context (BPM as a technology) and the business context (BPM as a management discipline), it is considered the most comprehensive [39, pp. 87-88].

Despite the great popularity of process-based management concepts and the benefits they bring, BPM is still not adopted as a practice in many organizations, particularly in those of the public sector. It is unclear what causes this lack of acceptance [42]. Moreover the term "adoption" in the context of BPM is seldom used in literature, although it seems to be analogous to the area of Enterprise Resource Planning (ERP)

TABLE I.

BPM CRITICAL SUCCESS FACTORS

\begin{tabular}{|c|c|}
\hline BPM CSFs & Source \\
\hline Top management support, Management involvement, Leadership. & $\begin{array}{l}\text { [3] Bai and Sarkis, 2013; [5] Bandara, Alibabaei and Aghdasi, 2009; [7] } \\
\text { Buh, Kovacic and Stemberger, } 2015\end{array}$ \\
\hline $\begin{array}{l}\text { Information technology, Development of service-oriented business } \\
\text { applications and adapting the IT infrastructure, IS support. }\end{array}$ & $\begin{array}{l}\text { [3] Bai and Sarkis, 2013; [5] Bandara, Alibabaei and Aghdasi, 2009; [7] } \\
\text { Buh, Kovacic and Stemberger, 2015; [31] Ravesteyn and Batenburg, 2010; } \\
\text { [11] De Bruin and Rosemann, 2005; [38] Skrinjar and Trkman 2013; [42] } \\
\text { Trkman, } 2010\end{array}$ \\
\hline $\begin{array}{l}\text { Strategic alignment, Alignment of processes to organizational } \\
\text { goals. }\end{array}$ & $\begin{array}{l}\text { [3] Bai and Sarkis, 2013; [5] Bandara et al, 2009; [7] Buh, Kovacic and } \\
\text { Stemberger, 2015; [11] De Bruin and Rosemann, 2005; [38] Skrinjar and } \\
\text { Trkman 2013; [42] Trkman, } 2010\end{array}$ \\
\hline $\begin{array}{l}\text { Governance, Clearly defined process owners, Appointment of } \\
\text { process owners. }\end{array}$ & $\begin{array}{l}\text { [7] Buh, Kovacic and Stemberger, 2015; [11] De Bruin and Rosemann, } \\
\text { 2005; [42] Trkman, } 2010\end{array}$ \\
\hline Methods, Methodology. & $\begin{array}{l}\text { [5] Bandara, Alibabaei and Aghdasi, 2009; [7] Buh, Kovacic and } \\
\text { Stemberger, 2015; [31] Ravesteyn and Batenburg, 2010; [11] De Bruin and } \\
\text { Rosemann, 2005 }\end{array}$ \\
\hline $\begin{array}{l}\text { Project management, Change Management, Ability to implement } \\
\text { the proposed changes. }\end{array}$ & $\begin{array}{l}\text { [3] Bai and Sarkis, 2013; [5] Bandara, Alibabaei and Aghdasi, 2009; [7] } \\
\text { Buh, Kovacic and Stemberger, 2015; [31] Ravesteyn and Batenburg, 2010; } \\
\text { [38] Skrinjar and Trkman 2013; [42] Trkman, } 2010\end{array}$ \\
\hline Performance measurement, Measurement and control. & $\begin{array}{l}\text { [3] Bai and Sarkis, 2013; [5] Bandara, Alibabaei and Aghdasi, 2009; [7] } \\
\text { Buh, Kovacic and Stemberger, 2015; [31] Ravesteyn and Batenburg, 2010; } \\
\text { [38] Skrinjar and Trkman 2013; [42] Trkman, } 2010\end{array}$ \\
\hline $\begin{array}{l}\text { People, Level of employee's specialization, Training and } \\
\text { empowerment of employees, Motivated employees. }\end{array}$ & $\begin{array}{l}\text { [5] Bandara, Alibabaei and Aghdasi, 2009; [7] Buh, Kovacic and } \\
\text { Stemberger, 2015; [11] De Bruin and Rosemann, 2005; [38] Skrinjar and } \\
\text { Trkman 2013; [42] Trkman, } 2010\end{array}$ \\
\hline Culture, Communication, Teamwork, Social Networks. & $\begin{array}{l}\text { [3] Bai and Sarkis, 2013; [5] Bandara, Alibabaei and Aghdasi, 2009; [7] Buh } \\
\text { et al., 2015; [11] De Bruin and Rosemann, } 2005\end{array}$ \\
\hline
\end{tabular}


systems research [13]. This is particularly notable if we wish to explore factors that can explain the use and acceptance of BPM assumptions in an organization [12], [16].

Previous BPM adoption studies that have used the "adoption" term have focused on success factors or single, selected aspects of BPM implementations and applications. Hribar and Mendling [16] in quantitative research analyzed the role of organizational culture for the successful adoption of BPM. According to this study organizational culture influences the success of BPM adoption. Moreover, this research includes an analysis of the types of organizational culture and indicates which culture types to a greater extent contribute to the success of BPM adoption and the resulting increased performance.

Malinova and Mendling [23] in their qualitative research proposed a conceptual framework for the adoption of BPM indicating possible causes of adoption, action and implementation strategies, and the anticipated effects of this adoption. However, there is no measuring instrument in the study, so it cannot serve as a model for adoption in accordance with the principles of modeling in organizational science [37]. Eikebrokk, Iden, Olsen and Opdahl [12] applied a similar approach to the analysis of factors that influence the acceptance and use of process modeling in organizations: a process modeling acceptance model was developed and tested empirically using survey data from companies.

In general, research on BPM devotes much more attention to BPM after the adoption decision. Studies on the entire BPM life cycle and studies examining different aspects of BPM maturity are definitely dominant. In addition to the afore mentioned studies of the type of culture as a predictor of successful BPM adoption [16] and research on the acceptance of BPM tools [12], literature sources on BPM prediction are virtually non-existent.

\section{BPM Critical Success Factors}

In the context of the successful adoption of BPM there have been several studies on critical success factors (CSFs) [3], [5], [7], [11], [31], [38], [42]. Researchers used different terms for identical factors frequently critical to the success of BPM. These terms include: matching processes to organizational strategies, selecting appropriate project management and management methods, supporting top management, using the right information technology, and building a BPM-driven organizational culture.

All these factors are important for understanding the factors behind a successful BPM adoption. However, the adoption model should provide predictability based on clearly defined assumptions and be precise and falsifiable [37]. A BPM adoption model should explain which factors are positive or negative predictors of BPM adoption. For this reason, a review of critical success factors diagnosed after BPM (expost) adoption may be a starting point to consider which of these factors can be predicted earlier. For example, if top management support is a BPM critical success factor, then this factor probably also occurred in other organizational change projects implemented in the organization. If top management did not support other projects, it can be assumed that it will not support BPM initiatives and programs. Thus, the review of BPM CSFs studies is the first step to diagnosing prediction factors and for the development of a BPM adoption model, which is missing in BPM research. Table I. presents a summary of a literature review on BPM CSFs.

\section{TOE as a Conceptual Framework for BPM Adoption}

To identify and group BPM adoption factors in an organization the TOE framework is applied. The technological context of the TOE concerns the availability of internal and external technologies and new technologies relevant to the organization; the organizational context describes the characteristics of the organization such as communication processes and internal resources; the environmental context refers to the environmental conditions in which the organization operates, e.g. nature and/or strength of competitors and government regulations [25], [4].

The TOE framework takes into account the three aforementioned perspectives important for the adoption of new solutions, and have therefore been chosen as the theoretical basis in various areas of IS research such as cloud computing adoption [2], [6], e-business adoption [25], enterprise resource planning systems (ERP) adoption [26] and e-government assimilation [28]. In BPM research, the TOE framework was used to study BPM software adoption [15]. In order to identify contextual factors a literature review on TOE

TABLE II.

FACTORs AfFeCting InNOvation's AdOPTION BASED ON TOE Framework

\begin{tabular}{|l|l|l|}
\hline & \multicolumn{1}{|c|}{ Factors in research using the TOE framework } & \multicolumn{1}{c|}{ Source } \\
\hline $\begin{array}{l}\text { Technological } \\
\text { Context }\end{array}$ & $\begin{array}{l}\text { Complexity, Compatibility, Satisfaction with existing } \\
\text { systems, Technology Competence, Technology } \\
\text { readiness, Technology integration. }\end{array}$ & $\begin{array}{l}\text { [2] Alshamaila, Papagiannidis and Li, 2013; [6] Borgman, Bahli, } \\
\text { Heier and Schewski, 2013; [9] Chau and Tam, 1997; [15] He and } \\
\text { Wang, 2014; [19] Ismail and Ali, 2013; [30] Ramdani, Kawalek } \\
\text { and Lorenzo, 2009; [45] Zhu, Kraemer and Dedrick, 2004; [46] } \\
\text { Zhu and Kraemer, 2005 }\end{array}$ \\
\hline $\begin{array}{l}\text { Organizational } \\
\text { Context }\end{array}$ & $\begin{array}{l}\text { Perceived benefits, Perceived costs, Perceived barriers, } \\
\text { Top management support, Organizational readiness, } \\
\text { Extent of coordination, Employees knowledge, } \\
\text { Financial commitment. }\end{array}$ & $\begin{array}{l}\text { [2] Alshamaila, Papagiannidis and Li, 2013; [6] Borgman, Bahli, } \\
\text { Heier and Schewski, 2013; [9] Chau and Tam, 1997; [19] Ismail } \\
\text { and Ali, 2013; [21] Kuan and Chau, 2001; [25] Oliveira and } \\
\text { Martins, 2010; [28] Pudjianto, Zo, Ciganek and Rho, 2011; [30] } \\
\text { Ramdani, Kawalek and Lorenzo, 2009; [46] Zhu and Kraemer, } \\
\text { 2005 }\end{array}$ \\
\hline $\begin{array}{l}\text { Environmental } \\
\text { Context }\end{array}$ & $\begin{array}{l}\text { Perceived environmental pressure, Market uncertainty, } \\
\text { Regulatory policy and support. }\end{array}$ & $\begin{array}{l}\text { [9] Chau and Tam, 1997; [21] Kuan and Chau, 2001; [25] Oliveira } \\
\text { and Martins, 2010; [26] Pan and Jang, 2008; [30] Ramdani, } \\
\text { Kawalek and Lorenzo, 2009; [47] Zhu, Dong, Xu and Kraemer, } \\
\text { 2006 }\end{array}$ \\
\hline
\end{tabular}


framework applications and on success factors of BPM implementations was conducted. Table II. provides an overview of the factors using in the research with TOE framework. The factors are grouped according to the technological, organizational and environmental context. Factors are listed according to the name under which they occur in the research. However, some names have the same meaning.

\section{RESEARCH PROCESS AND METHODOLOGY}

To identify the TOE factors that allow us to predict successful BPM adoption we used the methodology for constructing conceptual framework by Jabareen [20]. There are two main reasons why we have chosen this methodology. Firstly, this methodology defines framework as an integrated set of factors that enable the theoretical explanation of the studied phenomenon. Thus, according to this definition, the chosen methodology can be used for the preliminary identification of factors. Secondly, it is a methodology of qualitative research that can be based on literature review research, this being the initial step of every researcher as the necessary basis for developing new knowledge and systematizing the existing one [43], [20]. Moreover, the literature review creates a foundation for the development of new models and theories [43], and this is the main aim of proposed research: to create a foundation for the BPM adoption model.

Jabareen's methodology for building conceptual frameworks from existent multidisciplinary literature is a process of theorization [20]. According to the chosen research procedure, we have used in this study the following research steps presented on Figure 1. In the first step of our research process we collected, mapped, and read the literature sources. Our data sources search included literature on BPM in general, especially BPM critical success factors. The literature regarding the current applications of the TOE framework in the research on the adoption of new innovative solutions was also crucial. applications according to the same or very similar meaning. Results of this investigation present first and second column in Table III. In the next, key stage of the study (step 4 on Fig. 1), as a result of the subsequent deduction, we combined factors of the same meaning, while reducing their number. For example, the key success factor of strategic alignment shows that the organization can indicate the impact of processes on the implementation of strategic objectives. Thus, this factor allows an assessment of the expected costs and benefits of BPM implementation. Factors matching the concept in the framework of the TOE are: perceived benefits, perceived costs, perceived barriers. These factors can all be measured with the help of a factor "perceived strategic benefits of using BPM". This approach allows us to identify in the fifth step an initial list of factors predicting successful BPM adoption. This approach resulted from the most common objective for literature review being a combination of past literature aiming at "formulating general statements that characterize multiple specific instances of research, methods, theories, or practices" $[10$, p. 4].

\section{RESULTS AND DISCUSSION}

\section{Technological Context of BPM Adoption}

Technological factors of BPM adoption can refer to the information technologies that are dedicated to modeling, analysis, simulation, automation, and process management in general. "Complexity", defined as "the degree to which an innovation is perceived as relatively difficult to understand and use" [34, p. 257] is considered as one of the fundamental factors that adversely affect adoption in many past IT adoption studies [30], [19]. Based on results of the BPM software adoption study [15], we suggest the same relationship for BPM in general, i.e. that the complexity of a BPM system and notation has a negative effect on the BPM adoption.

The adoption of BPM can also be affected by other relationships between processes and information technology

\begin{tabular}{|c|c|c|c|c|}
\hline Step I & Step 2 & Step 3 & Step 4 & Step 5 \\
\hline $\begin{array}{l}\text { Collecting, mapping, } \\
\text { and reading of literature } \\
\text { regarding BPM CSFs and } \\
\text { practical applications of } \\
\text { TOE framework }\end{array}$ & $\begin{array}{l}\text { Extracting and } \\
\text { synthesizing of } \\
\text { BPM CSFs and } \\
\text { TOE factors from } \\
\text { the literature }\end{array}$ & $\begin{array}{l}\text { Categorizing CSFs } \\
\text { and TOE factors } \\
\text { according to the } \\
\text { same or very } \\
\text { similar meaning }\end{array}$ & $\begin{array}{l}\text { Integrating } \\
\text { factors based on } \\
\text { the resulting } \\
\text { deduction }\end{array}$ & $\begin{array}{l}\text { Identifying factors } \\
\text { predicting successful } \\
\text { BPM adoption based } \\
\text { on fitting BPM CSFs } \\
\text { and TOE factors }\end{array}$ \\
\hline
\end{tabular}

Fig. 1 Research process to identify initial list of factors predicting successful BPM adoption

In the second step of our research process (Fig. 1), we reviewed and synthesized the critical success factors for BPM, as presented in Table I. Also, the factors used in the TOE studies were collected and grouped by technological, organizational, and, environmental context. Findings of this research step are included in Table II.

In the next, third step, we categorized the factors found in the literature, both BPM CSFs and those used in the TOE
(IT), such as Business-IT alignment [22], [42] or the adoption of ERP systems, where a process-driven approach is commonly used in system implementations [27], [13]. Reference [9] note that the satisfaction level with existing IT systems plays a significant role in the shaping of motivations to change. Satisfaction with existing processes that are automated in ERP systems, or, satisfaction with service delivery processes through IT, may discourage organizational 
TABLE III.

FITTING OF BPM CSFS AND TOE FACTORS

\begin{tabular}{|c|c|c|}
\hline BPM CSFs & TOE factors & TOE factors for BPM \\
\hline $\begin{array}{l}\text { Top management support, Management involvement, } \\
\text { Leadership }\end{array}$ & Top management support & $\begin{array}{l}\text { Top management support for previous } \\
\text { projects of organizational change }\end{array}$ \\
\hline $\begin{array}{l}\text { Information technology, Development of service- } \\
\text { oriented business applications and adapting the IT } \\
\text { infrastructure, IS support }\end{array}$ & $\begin{array}{l}\text { Complexity / Compatibility } \\
\text { Satisfaction with existing systems } \\
\text { Technology competence / readiness / } \\
\text { integration }\end{array}$ & $\begin{array}{l}\text { Complexity of BPM system and notation } \\
\text { Satisfaction with existing systems } \\
\text { Business-IT alignment level }\end{array}$ \\
\hline $\begin{array}{l}\text { Strategic alignment, Alignment of processes to } \\
\text { organizational goals }\end{array}$ & $\begin{array}{l}\text { Perceived benefits / costs / barriers / } \\
\text { Financial commitment }\end{array}$ & Perceived strategic benefits of using BPM \\
\hline $\begin{array}{l}\text { Governance, Clearly defined process owners, } \\
\text { Appointment of process owners }\end{array}$ & Extent of coordination & Extent of coordination \\
\hline Methods, Methodology & Organizational readiness & Organizational readiness \\
\hline $\begin{array}{l}\text { Project management, Change Management, Ability } \\
\text { to implement the proposed changes }\end{array}$ & Organizational readiness & Organizational readiness \\
\hline Performance measurement, Measurement and control & & Performance measurement \\
\hline $\begin{array}{l}\text { People, Level of employee's specialization, Training } \\
\text { and empowerment of employees, Motivated } \\
\text { employees }\end{array}$ & Employees knowledge & $\begin{array}{l}\text { Culture conducive to organizational } \\
\text { changes }\end{array}$ \\
\hline \multirow[t]{2}{*}{$\begin{array}{l}\text { Culture, Communication, Teamwork, Social } \\
\text { Networks }\end{array}$} & & $\begin{array}{l}\text { Culture conducive to organizational } \\
\text { changes }\end{array}$ \\
\hline & $\begin{array}{l}\text { Perceived environmental pressure / } \\
\text { market uncertainty / Regulatory } \\
\text { policy and support }\end{array}$ & Perceived environmental pressure \\
\hline
\end{tabular}

changes. Thus, the next technological factor concerns the Business-IT alignment level: the higher the technological factor the more positive the impact on BPM adoption. However, satisfaction with existing systems has a negative effect on the BPM adoption. The more an organization is satisfied with its systems, the less it wants to change the processes to which it is accustomed.

\section{Organizational Context of BPM Adoption}

The TOE organizational context refers to the characteristics, structures, processes, and resources of an organization that may constrain or facilitate the adoption of innovation [9], [19]. The first factor takes into consideration the perceived strategic benefits of BPM. Awareness of benefits such as efficiency, effectiveness, and agility [35] can be a basic driver of a decision to adopt. Therefore, the hypothesis is formulated as follows: perceived benefits of using BPM have a positive effect on the BPM adoption.

Top management support is one of the most commonly mentioned CSFs, not only for BPM, but also for all organizational change projects. Effective decisions, monitoring and promoting acceptance of the project, and general change of management from the top, are crucial for a successful BPM adoption [1], [3]. The supporting role of top management in the previous change projects can be also a positive predictor for BPM adoption. Therefore, top management support has a positive effect on BPM adoption.

Organizational readiness is defined in research on innovation adoption as "the availability of the needed organizational resources for adoption" [18, p. 467], [2], [19]. Of particular importance is the perceived assessment by managers on the financial resources held by the organization and the organizational competence to undertake the adoption. This viewpoint confirms studies on BPM CSFs [3], [31]. The following statement is therefore suggested: organizational readiness has a positive effect on BPM adoption.

Coordination mechanisms can take the form of "processes, roles, or structural arrangements [...] as teams, informal linking roles, like those of change agents" [8], [28]. This factor seems highly important in the context of the development of BPM governance that establishes appropriate and transparent roles and responsibilities for BPM [11]. The resulting factor is the extent of coordination. The use of a coordination mechanism can have a positive effect on BPM adoption.

Performance measurement does not exist in previous studies using the TOE framework. However, the need to measure the effectiveness of the organization and its processes, and the inclusion of process performance measurement for continuous process improvement, are essential to the high level of BPM adoption and organizational maturity [31], [42]. The need for performance measurement results from strategic considerations and fosters the adoption of BPM. This result in the identification of the factor investigating the use of performance measurement, what can have a positive effect on BPM adoption.

Factors regarding organizational culture have not been mentioned so far in research using the TOE framework. 
Probably because it was difficult to measure the impact of this factor in the context of adopting new technologies and innovations. However, in the area of BPM research there are strong arguments in the work of Hribar and Mendling [16] indicating the type of organizational culture that creates an environment for BPM. The results of these tests will allow to build an appropriate measurement instrument and thus to include the cultural factor in the BPM adoption model. BPM's adoption is very strongly linked to cultural and human aspects [11], [16] and so we believe that this factor must be included in the model.

\section{Environmental Context of BPM Adoption}

BPM adoption can be the result of pressure exerted on an enterprise by its environment or external circumstances. Pressure can be exerted by business partners, competitors or government policies [21], [14]. A study of McCormack and Johnson [24] indicates that BPM maturity in a least advanced organization determines the level of cooperation and adaptation of inter-organizational processes. External conditions can also force the adoption of BPM in an organization, when, for example, the improvement and development of internal processes is forced upon it as the result of feedback from customers and suppliers [14], [38], [7]. In summary, perceived environmental pressure can have a positive effect on BPM adoption.

\section{CONCLUSION}

In this research we explored the factors that create environments receptive or unreceptive to BPM adoption and use. Factors have been identified within the TOE framework and grouped by the technological, organizational and environmental context.

The method of literature review and its qualitative analysis was used to identify factors. Table IV. presents the results of the study. As indicated in the title, this research paper presents initial steps for BPM model development. A review of prior literature and identifying of preliminary list of factors that can predict successful BPM adoption creates a foundation for future research and facilitates theory and model development.

The identified list of factors is the foundation for the BPM adoption model which has not been proposed in studies so far.

\section{FUTURE RESEARCH}

The initial identification of BPM adoption factors presented in this research is the basis for the development of the adoption model. However, as such factors have not yet been investigated, further studies are needed to verify the initial proposed list of factors. Subsequent research should be of qualitative and quantitative research. In order to verify factors derived from the literature review and perhaps adding new ones, a multiple case study method could be applied. This multiple case study analysis is considered the most suitable in examining organizations that adopted BPM within the reallife context. We plan to use a qualitative study with the aim of developing relevant hypotheses for future quantitative
TABLE IV.

BPM ADOPTION FACTORS BASED ON TOE FRAMEWORK

\begin{tabular}{|l|l|}
\hline $\begin{array}{l}\text { Technological } \\
\text { Context }\end{array}$ & $\begin{array}{l}\text { TOE factors for BPM adoption } \\
\text { notation } \\
\text { Satisfaction with existing systems } \\
\text { Business-IT alignment level }\end{array}$ \\
\hline $\begin{array}{l}\text { Organizational } \\
\text { Context }\end{array}$ & $\begin{array}{l}\text { Top management support for previous } \\
\text { projects of organizational change } \\
\text { Perceived strategic benefits of using } \\
\text { BPM } \\
\text { Extent of coordination } \\
\text { Organizational readiness } \\
\text { Performance measurement } \\
\text { Culture conducive to organizational } \\
\text { changes }\end{array}$ \\
\hline $\begin{array}{l}\text { Environmental } \\
\text { Context }\end{array}$ & \begin{tabular}{l} 
Perceived environmental pressure \\
\hline
\end{tabular}
\end{tabular}

research on the phenomena. Thus, to develop BPM adoption model we plan further research aims: to examine identified factors in a qualitative study, and then formulate and test research hypothesis based on qualitative research. To develop a model to explain BPM adoption is our target aim.

\section{CONTRIBUTION}

The results of the proposed research could contribute to the development of a consistent theoretical model that would include the various factors influencing the successful adoption of BPM and thus contribute to the theory development. The methodological approach utilizing the TOE framework as the basis of the adoption model is novel in BPM research.

The proposed initial list of BPM adoption factors may provide the foundation for further research. This list can be developed and modified using other data sources and types of research mentioned in the section about future research.

The exploration of BPM adoption factors can contribute to the development of both individuals and entire organizations, and in both the public and private sectors. For individual employees and managers, it will be possible to raise awareness of BPM and identify gaps in competency delaying the adoption of BPM. At an organizational level, the model will help streamline organizational planning and resource development in all areas of the TOE framework. Knowledge about factors influencing successful BPM adoption can help predict the effects of BPM application in organizations that are less mature. A high level of BPM adoption allows an increase in the efficiency of processes carried out for citizens in the public and customers in the private sector, thus benefiting a country as a whole.

\section{REFERENCES}

[1] Al-Mudimigh, A. S. (2007). "The role and impact of business process management in enterprise systems implementation." Business Process Management Journal 13 (6), 866-874. 
[2] Alshamaila, Y., S. Papagiannidis, and F. Li (2013). "Cloud computing adoption by SMEs in the north east of England: A multi-perspective framework." Journal of Enterprise Information Management 26 (3), 250-275.

[3] Bai, C. and J. Sarkis (2013). "A Grey-Based DEMATEL Model for Evaluating Business Process Management Critical Success Factors." International Journal of Production Economics 146 (1), 281-292.

[4] Baker, J. (2012). "The technology-organization-environment framework." In: Dwivedi, Y. K., M. R. Wade, and S. L. Schneberger (eds.) Information Systems Theory. New York: Springer, pp. 231-245.

[5] Bandara, W., A. Alibabaei and M. Aghdasi (2009). "Means of achieving Business Process Management success factors." In: Proceedings of the 4th Mediterranean Conference on Information Systems, 25-27 September 2009, Athens University of Economics and Business, Athens.

[6] Borgman, H. P., B. Bahli, H. Heier and F. Schewski (2013). "Cloudrise: exploring cloud computing adoption and governance with the TOE framework." In: Proceedings of the 46th Hawaii International Conference on System Sciences (HICSS). IEEE, pp. 4425-4435.

[7] Buh, B., A. Kovacic and M. I. Stemberger (2015). "Critical Success Sactors for Different Stages of Business Process Management Adoption - a Case Study." Economic Research-Ekonomska Istraživanja 28 (1), 243-258.

[8] Chatterjee, D., R. Grewal and V. Sambamurthy (2002). "Shaping up for e-commerce: institutional enablers of the organizational assimilation of web technologies." MIS Quarterly 26 (2), 65-89.

[9] Chau, P. Y. K. and K. Y. Tam (1997). "Factors affecting the adoption of open systems: an exploratory study.” MIS Quarterly, 1997, 21 (1), $1-24$.

[10] Cooper, H. and L. V. Hedges (2009). "Research synthesis as a scientific process" In: Cooper, H., L. V., Hedges and J. C. Valentine (Eds.). The handbook of research synthesis and meta-analysis. Russell Sage Foundation.

[11] De Bruin, T. and M. Rosemann (2005). "Towards a Business Process Management Maturity Model." In: Proceedings of the Thirteenth European Conference on Information Systems, ECIS, 26-28 May 2005, Germany, Regensburg.

[12] Eikebrokk, T. R., J. Iden, D. H. Olsen and A. L. Opdahl (2011). "Understanding the determinants of business process modelling in organisations.” Business Process Management Journal 17 (4), 639-662.

[13] Gabryelczyk, R. and N. Roztocki (2017). "Effects of BPM on ERP Adoption in the Public Sector." In: Proceedings of the 23rd Americas Conference on Information Systems (AMCIS). Boston, USA: AIS Library. URL: http://aisel.aisnet.org/amcis2017/AdvancesIS/Presentations/14/

[14] Gabryelczyk, R. and N. Roztocki (2018). "Business Process Management Success Framework for Transition Economies." Information Systems Management 35(3), 234-253.

[15] He, Y. and W. Wang (2014). "BPM software adoption in enterprises based on TOE framework and IS success model." Computer Modelling \& New Technologies 18 (12C), 195-200.

[16] Hribar, B. and J. Mendling (2014). "The Correlation of Organizational Culture and Success of BPM Adoption." In: Proceedings of the European Conference on Information Systems (ECIS). Tel Aviv, Israel: AIS Library. URL: http://aisel.aisnet.org/ecis2014/proceedings/track06/2

[17] Houy, C., P. Fettke and P. Loos (2010). "Empirical Research in Business Process Management - Analysis of an Emerging Field of Research.” Business Process Management Journal 16 (4), 619-661.

[18] Iacovou, C. L., I. Benbasat, and A. S. Dexter (1995). "Electronic data interchange and small organizations: Adoption and impact of technology." MIS Quarterly 19 (4), 465-485, p. 467.

[19] Ismail, W. and A. Ali (2013). "Conceptual Model for Examining the Factors that Influence the Likelihood of Computerised Accounting Information System (CAIS) Adoption Among Malaysian SME." International Journal of Information Technology and Business Management 15 (1), 122-151.

[20] Jabareen, Y. (2009). "Building a Conceptual Framework: Philosophy, Definitions, and Procedure." International Journal of Qualitative Methods, 8(4), 49-62.

[21] Kuan, K. K., and P. Y. Chau (2001). "A perception-based model for EDI adoption in small businesses using a technology-organizationenvironment framework.” Information \& management 38 (8), 507-521.
[22] Luftman, J. (2000). “Assessing Business-IT Alignment Maturity". Communications of the Association for Information Systems 4 (14). AIS Library. URL: http://aisel.aisnet.org/cais/vol4/iss1/14

[23] Malinova, M. and J. Mendling (2013). "A Qualitative Research Perspective on BPM Adoption and the Pitfalls of Business Process Modeling." Lecture Notes in Business Information Processing, LNBIP 132, 77-88. Berlin Heidelberg: Springer.

[24] McCormack, K. P. and W. C. Johnson (2001). Business process orientation: Gaining the e-business competitive advantage. CRC Press.

[25] Oliveira, T. and M. F. Martins (2010). "Understanding e-business adoption across industries in European countries." Industrial Management \& Data Systems 110 (9), 1337-1354.

[26] Pan, M. J., and W. Y. Jang (2008). "Determinants of the adoption of enterprise resource planning within the technology-organizationenvironment framework: Taiwan's communications industry.” Journal of Computer Information Systems 48 (3), 94-102.

[27] Panayiotou, N.A., S. P. Gayialis, N. P. Evangelopoulos and P. K. Katimertzoglou (2015). "A business process modeling-enabled requirements engineering framework for ERP implementation." Business Process Management Journal 21 (3), 628-664.

[28] Pudjianto, B., H. Zo, A. P. Ciganek and J. J. Rho (2011). "Determinants of e-government assimilation in Indonesia: An empirical investigation using a TOE framework." Asia Pacific Journal of Information Systems 21 (1), 49-80.

[29] Ram, J. and D. Corkindale (2014). "How 'critical' are the critical success factors (CSFs)?: Examining the role of CSFs for ERP." Business Process Management Journal 20 (1), 151-174.

[30] Ramdani, B., P. Kawalek and O. Lorenzo (2009). "Predicting SMEs' adoption of enterprise systems." Journal of Enterprise Information Management 22 (1/2), 10-24.

[31] Ravesteyn, P. and R. Batenburg (2010). "Surveying the Critical Success Factors of BPM-Systems Implementation." Business Process Management Journal 16 (3), 492-507.

[32] Recker J. (2015). "Evidence-Based Business Process Management: Using Digital Opportunities to Drive Organizational Innovation.” In: vom Brocke J. and T. Schmiedel (eds). BPM - Driving Innovation in a Digital World. Management for Professionals. Cham: Springer, pp. 129-143.

[33] Reijers, H.A. (2006). "Implementing BPM systems: the role of process orientation.” Business Process Management Journal 12 (4), 389-409.

[34] Rogers, E. M. (2003). Diffusion of innovations. Fourth Edition. New York: Free Press. p. 257

[35] Rudden, J. (2007). "Making the Case for BPM-A Benefits Checklist." BPTrends January 2007.

[36] Schmiedel, T. and J. vom Brocke (2015). "Business Process Management: Potentials and Challenges of Driving Innovation." In: vom Brocke J. and T. Schmiedel (eds). BPM - Driving Innovation in a Digital World. Management for Professionals. Cham: Springer, pp. 3 15.

[37] Shapira, Z. (2011). "I've Got a Theory Paper-Do You?: Conceptual, Empirical, and Theoretical Contributions to Knowledge in the Organizational Sciences.” Organization Science 22 (5), 1312-1321.

[38] Skrinjar, R. and P. Trkman (2013). "Increasing Process Orientation with Business Process Management: Critical Practices.” International Journal of Information Management 33 (1), 48-60.

[39] Swenson, K. D. and M. von Rosing (2015). "Phase 4: What Is Business Process Management?” In: von Rosing M., H. von Scheel and A.-W. Scheer (eds.). The Complete Business Process Handbook. Body of Knowledge from Process Modeling to BPM. 1st Edition. Morgan Kaufmann, p. 87.

[40] Tarafdar, M. and S. R. Gordon (2007). "Understanding the influence of information systems competencies on process innovation: A resourcebased view." The Journal of Strategic Information Systems 16 (4), 353392.

[41] Tornatzky, L.G. and M. Fleischer (1990). The Processes of Technological Innovation. Lexington Books.

[42] Trkman, P. (2010). "The Critical Success Factors of Business Process Management." International Journal of Information Management 30 (2), 125-134.

[43] Webster, J. and R. T. Watson (2002). "Analyzing the past to prepare for the future: Writing a literature review." MIS Quarterly, xiii-xxiii.

[44] vom Brocke, J., S. Zelt and T. Schmiedel (2016). "On the Role of Context in Business Process Management." International Journal of Information Management 36 (3), 486-495. 
[45] Zhu, K., K. L. Kraemer and J. Dedrick, (2004). "Information technology payoff in e-business environments: An international perspective on value creation of e-business in the financial services industry." Journal of Management Information Systems, 21(1), 17-54.

[46] Zhu, K. and K. L. Kraemer (2005). "Post-adoption variations in usage and value of e-business by organizations: cross-country evidence from the retail industry." Information Systems Research, 16(1), 61-84.
[47] Zhu, K., S. Dong, S. X. Xu, and K. L. Kraemer (2006). "Innovation diffusion in global contexts: determinants of post-adoption digital transformation of European companies." European Journal of Information Systems 15 (6), 601-616. 